\title{
A Case of Familial Male-limited Precocious Puberty with a Novel Mutation
}

\author{
(1) Shilpa Gurnurkar1,2, (1) Emily DiLillo1, (1) Mauri Carakushansky1,2 \\ ${ }^{1}$ Nemours Children's Hospital, Clinic of Pediatrics, Florida, USA \\ ${ }^{2}$ Nemours Children's Hospital, Clinic of Pediatrics, Division of Pediatric Endocrinology, Florida, USA
}

\section{What is already known on this topic?}

Familial male-limited precocious puberty (FMPP) is a very rare cause of precocious puberty seen exclusively in males, which results in early onset puberty, rapid skeletal maturation and compromised final adult height, if not treated. Very limited data is available regarding treatment and there are no consensus guidelines.

\section{What this study adds?}

We report a novel mutation in the luteinizing hormone/chorionic gonadotropin receptor LHCGR gene causing FMPP in a very young child who presented with puberty at six months of age and is being successfully treated. Our report adds to the very scarce information available about this condition.

\section{Abstract}

Familial male-limited precocious puberty (FMPP), also known as testotoxicosis, is a rare cause of precocious puberty in males. It is caused by a mutation in the luteinizing hormone/chorionic gonadotropin receptor (LHCGR) gene, resulting in the receptor being constitutively activated. This causes excessive production of testosterone, leading to precocious puberty in males. Generally, boys present with signs of puberty, such as pubic hair growth, acne, and increased height velocity around the age of 2-4 years old. Like any other cause of precocious puberty, the goal of treatment is to prevent virilization and also delay closure of the epiphyseal plates to maintain adult height potential. Treatment, therefore, is aimed at decreasing the effects of testosterone, as well as stopping the conversion of testosterone to estrogen. Little is known about the long-term effects of treatment because the disorder is so rare. However, studies using bicalutamide and anastrozole have been promising. In this report, we present a boy with FMPP with a novel mutation in the LHCGR gene, who has been responding well to therapy using both drugs.

Keywords: Familial male-limited precocious puberty, bone age, short stature, adult height

\section{Introduction}

The luteinizing hormone/chorionic gonadotropin receptor (LHCGR), a G-protein coupled receptor, is present on multiple cell types, including ovarian theca cells, granulosa cells, and testicular Leydig cells (1). Under normal conditions, it is activated by LH and human chorionic gonadotropin (hCG). It is important for normal sexual development and production of sex steroids (1). The gene for the LHCGR is located on chromosome $2 \mathrm{p} 21$, and is the genetic basis of familial male-limited precocious puberty (FMPP), also known as testotoxicosis.

An activating mutation in the LHCGR gene may occur de novo or may be inherited in an autosomal dominant manner. The commonly reported genetic mutation is due to a substitution of an A to a $G$, which causes a change from aspartate to glycine, in position 578 of the LHCGR (2). This small change causes the protein to be constitutively
Address for Correspondence: Shilpa Gurnurkar MD, Nemours Children's Hospital, Orlando, Florida Phone: +407-558-1161 E-mail: shilpa.gurnurkar@nemours.org ORCID: orcid.org/0000-0002-8572-5160
Conflict of interest: None declared Received: 02.04 .2020 Accepted: 07.07.2020

${ }^{\circ}$ Copyright 2021 by Turkish Pediatric Endocrinology and Diabetes Society

The Journal of Clinical Research in Pediatric Endocrinology published by Galenos Publishing House. 
activated without any input from $\mathrm{LH}$, leading to excessive sex hormone production.

Interestingly, activating LHCGR mutations only affect phenotype in males. There are two proposed theories as to why females are not affected: LH and follicle stimulating hormone are both required to stimulate hormone synthesis, and that the activation of LH receptor (LHR) alone would not cause symptoms (2). Additionally, it is proposed that the degree of dysfunction is simply not high enough to cause symptoms (3). Regardless, the excessive production of testosterone causes early signs of puberty, such as pubic hair growth, increased penile length and acne, from direct effects of testosterone and dihydrotestosterone on the testosterone receptor, as well as increased height velocity with significant bone age advancement from conversion of androgens to estrogen by the enzyme aromatase. Boys generally present with symptoms around the age of 2-4 years old. Without treatment, rapid skeletal maturation occurs with a negative impact on final adult height.

Treatment goals are twofold: to decrease the effects of testosterone, typically through the use of anti-androgen agents; and to inhibit the conversion of testosterone to estrogen through the use of aromatase inhibitors. Multiple different medications have been trialed, but most recent studies show promising results using bicalutamide (an anti-androgen agent), and anastrozole (a third-generation aromatase inhibitor) $(4,5,6,7,8)$. Little is known about the long-term effects of treatment because the disorder is so rare. However, studies using bicalutamide and anastrozole have shown improved height potential $(5,6)$. In one study, final adult height was only 0.4 standard deviations below that of the general US male population (6).

Here, we present a boy with FMPP, with a novel mutation in the LHCGR gene, who has been responding well to bicalutamide and anastrozole therapy with marked decrease in growth velocity, pubertal progression and skeletal advancement.

\section{Case Report}

A 16-month-old male presented to our pediatric endocrinology clinic due to concerns about precocious puberty. His parents noticed presence of pubic hair at six months of age and also reported rapid growth acceleration. Parents denied exposure to creams, gels, or medications containing testosterone and there was no known history of early puberty or short stature in the family. Upon presentation, his height was over the $99^{\text {th }}$ percentile while his target height was at the $50^{\text {th }}$ percentile. Physical examination revealed prepubertal testes with pubic hair at Tanner stage 2. A bone age was obtained by his pediatrician, that was reported as $12-18$ months at a chronologic age of 12 months.

Initial lab evaluation revealed normal serum levels of 17-hydroxyprogesterone, androstenedione and dehydroepiandrosterone sulfate with a slightly elevated serum LH level $[0.7 \mathrm{mIU} / \mathrm{mL}$ (prepubertal $<0.3 \mathrm{mIU} /$ $\mathrm{mL})$ ], and a significantly elevated serum testosterone level [289 ng/dL ( $<5 \mathrm{ng} / \mathrm{dL})]$. A leuprolide stimulation test was performed that ruled out central precocious puberty and an adrenocorticotropic hormone stimulation test was also performed that ruled out congenital adrenal hyperplasia. His baseline serum testosterone during the test was $550 \mathrm{ng} / \mathrm{dL}$. A magnetic resonance imaging study of the abdomen and pelvis was reported to be normal. Scrotal ultrasound was obtained that revealed pre-pubertal testes with no testicular masses but testicular microliths were noted bilaterally. An $\alpha$-fetoprotein level was initially elevated, but repeat was normal, and serum $\beta$-hCG level was normal. Serum insulinlike growth factor-1 and thyroid function were also normal. Rapid skeletal maturation was noted with his bone age advanced to six years at a chronological age of 21 months and to eight years by 26 months of age. At 26 months of age, his stretched penile length was $11 \mathrm{~cm}$. At this time, the likely differential diagnoses were FMPP and McCuneAlbright syndrome. LHR testing was therefore obtained, which revealed a novel heterozygous missense mutation in the LHCGR gene (c.1733A > C; p.Asp.578Ala). The mutation was reported to be a variant of unknown significance though likely in the pathological end of the spectrum by variant analysis with SIFT and PolyPhen.

Based on the patient's classic presentation along with the genetic testing results, he was diagnosed to have FMPP and started on treatment with anastrozole $1 \mathrm{mg}$ daily and bicalutamide $25 \mathrm{mg}$ daily at two years and nine months of age. There was some parental hesitation in starting treatment, which delayed it by a few months.

The patient has been tolerating treatment well for over two years at the time of writing with a significant improvement in his linear growth, skeletal maturation and final height prediction (see Figure 1). The bone age to chronological age ratio has decreased from 4.5 at treatment initiation to 3.2 at two years after treatment. His predicted adult height as has improved from significantly below the $3^{\text {rd }}$ percentile to $162.5 \mathrm{~cm}$ which is at the $3^{\text {rd }}$ percentile. Annual scrotal ultrasound testing has revealed stable testicular microliths. Testes have remained prepubertal on exam with prepubertal early morning serum LH levels and prepubertal response to annual leuprolide stimulation testing. After approximately 14 months of treatment, he developed minimal gynecomastia bilaterally, which is a known side effect of androgen receptor antagonists. 
2 to 20 years: Boys Stature-for-age and Weight-for-age percentiles
NAME

$$
\text { RECORD \# }
$$

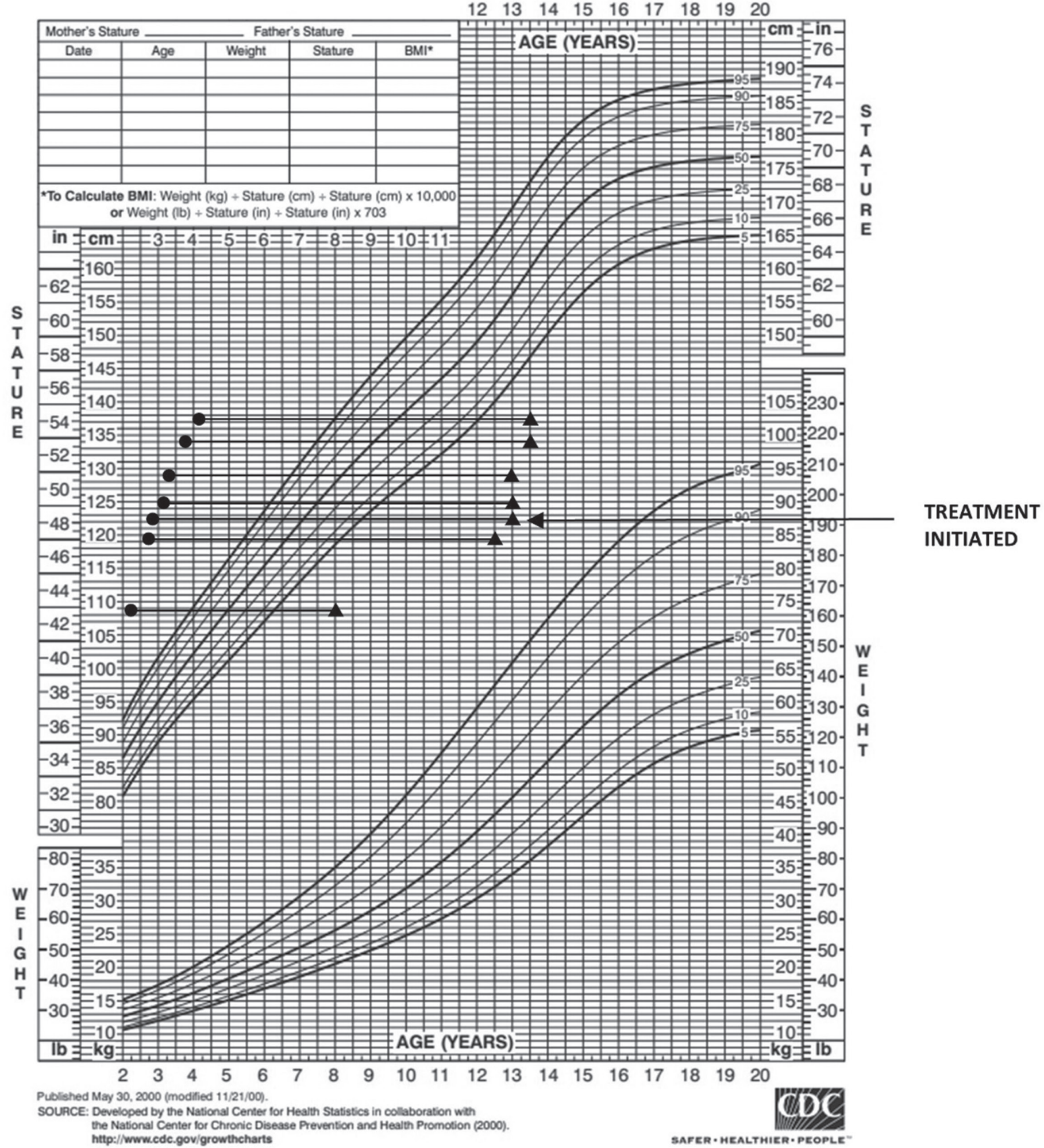

Figure 1. Patient's growth chart indicating height measurements with corresponding bone age readings before and after treatment initiation 


\section{Discussion}

FMPP is a rare cause of peripheral precocious puberty, exclusively affecting males. Affected males present with early onset of puberty, typically by the age of three years, accompanied by accelerated skeletal maturation resulting in premature epiphyseal fusion and compromised final adult height. The overall goal of treatment in FMPP is the same as for any cause of precocious puberty - to minimize virilization and maximize adult height potential.

In the short term, treatment efficacy is monitored using two criteria: physical examination to assess clinical progression; and bone ages to assess skeletal maturation and growth potential. The rarity and differences in phenotype of the condition make it difficult to do widespread clinical trials. Treatment has, however, evolved over the years but there is still no consensus on the optimal treatment.

Prior to the discovery that FMPP was due to an activating mutation of the $L H C G$ receptor gene, gonadotropin-releasing hormone (GnRH) agonists were the primary treatment. Once the pathophysiology was better understood, anti-androgen medications such as Medroxyprogesterone acetate and cyproterone initially, and ketoconazole later, became the mainstay for treatment. The former two medications failed to show an improvement in height potential and the latter was associated with serious side effects, such as hepatotoxicity and adrenal suppression (9).

It was during this time that adding aromatase inhibitors was trialed in order to prevent early growth plate closure $(8,10,11)$. Spironolactone (a weak anti-androgen) and testolactone (an aromatase inhibitor) were trialed with moderate success, and resulted in improvements in skeletal maturation, acne, aggressive behavior, and spontaneous erections $(10,11)$. However, in one study, all boys ended up with secondary central precocious puberty (10). The development of central precocious puberty was likely due to continued elevated poor androgen receptor blockade $(6,12,13)$. The fact that patients needed to discontinue spironolactone during gastro-intestinal illnesses, and the fact that it requires multiple daily doses, likely lead to poor compliance. All patients then required addition of deslorelin (a GnRH agonist) (10). Since that trial, more specific and potent medications have become available.

Most recent studies have shown good outcomes with anti-androgens such as bicalutamide and third generation aromatase inhibitors such as anastrozole $(4,6,7,8)$. These treatments, in conjunction with one another, have shown better adult height potential preservation than either alone (5). In one study, anti-androgens alone did not prevent early growth plate closure (5), and in another, anastrozole was ineffective in treating continued aggressiveness (7). Bicalutamide and anastrozole offer the additional advantage of a prolonged half-life that allows for convenient once-daily dosing while other anti-androgen agents would require multiple daily doses.

The data is somewhat variable in regards to long-term outcomes, but results are promising. Adult height is improved following treatment, though adults with FMPP are still slightly below average in height $(5,6)$. Long-term effects on fertility are still unknown, however one study did not show any differences in sperm count between patients taking anastrozole and controls (14). Patients seem to have preserved fertility in case reports (15). Until long-term data on adult height, fertility and bone health are available from a larger sample of patients, this combination therapy should be used judiciously. Endocrinologists should also keep in mind that the cost of therapy using bicalutamide and anastrozole is relatively more expensive than previous treatments (4).

Some studies have attempted to establish an association between phenotype and genotype $(16,17)$, which may alter treatment strategy due to variability in medication effectiveness. The traditional mutation in FMPP is Asp578Gly, resulting in an activation of LHCGR (2). However, other mutations have been known to cause FMPP (13). Approximately $55 \%$ of these "other" activating mutations occur at the 578 position, changing the aspartate residue a tyrosine, histidine, glycine, or glutamine (1).

To our knowledge, our patient has a novel mutation in the LHCGR gene, with a change from an A to a C, changing aspartate to alanine in the 578 position. Our patient has been responding well to therapy, likely because he has a mutation in the "typical" spot. However, this new mutation could explain some of the phenotypic differences in our patient compared to the typical FMPP patient. Typically, FMPP presents at the age of $2-4$ years. Our patient had initial symptoms much earlier than that at six months of age, which has only been documented in a handful of cases (13).

What remains unknown is what long-lasting effects remain from these increased hormone levels. It is known that testosterone has effects on the brain and on behavior, and increased levels can lead to aggressiveness, attention deficit hyperactivity disorder and developmental issues (3). Though duration of the androgen exposure may be related to level of aggressiveness in children (18), and this aggressiveness tends to disappear with treatment (11), there are no studies examining the long-term effects. 
Additionally, our patient had bilateral testicular microlithiasis. Typically found incidentally, testicular microliths occur with a prevalence of $2.4-5.6 \%$ in asymptomatic pediatric patients (19). Their cause is unknown, but it is thought to be a degenerative process in the seminiferous tubules leading to accumulation of cellular debris, and then accumulation of glycoproteins surrounding the debris, which then calcifies $(20,21)$. It is noted that testicular microliths do not typically affect Leydig cells, and maybe associated with Sertoli cell dysfunction (19). However, there is some evidence that microliths are associated with Leydig cell hyperplasia in rats (22). They are seen more frequently in children with Down syndrome and associated with testicular torsion, varicocele, retractile testes, cryptorchidism, inguinal hernias, and testicular neoplasms, though there is no evidence that they are premalignant $(19,20)$.

The microliths in our patient may well be an incidental finding. However, testicular changes have been observed in FMPP in more than one case. Premature differentiation in all major testicular cell types, seminomas, and germ cell neoplasia in situ $(13,15)$, and in particular, Leydig cell hyperplasia $(2,3,13)$, have all been reported. Given the recent findings of microliths being associated with Leydig cell hyperplasia, and the known association between FMPP and Leydig cell hyperplasia, there may be a link between the two (2). Despite this, there has only been one other report of testicular microlithiasis (13).

\section{Conclusion}

FMPP is a rare disorder that is still being studied. No treatment guidelines have been established for this condition. Definitive evidence of effective treatment modalities has been weak, primarily because of the limited number of reported cases, small sample sizes, and short-term outcomes. However, this case study adds to the literature by demonstrating a novel mutation that responded well to a combination of bicalutimide and anastrozole.

\section{Ethics}

Informed Consent: Yes, from patient's mother.

Peer-review: Externally peer-reviewed.

\section{Authorship Contributions}

Surgical and Medical Practices: Shilpa Gurnurkar, Concept: Shilpa Gurnurkar, Data Collection or Processing: Shilpa Gurnurkar, Emily DiLillo, Mauri Carakushansky, Literature Search: Shilpa Gurnurkar, Emily
DiLillo, Mauri Carakushansky, Writing: Shilpa Gurnurkar, Emily DiLillo, Mauri Carakushansky.

Financial Disclosure: The authors declared that this study received no financial support.

\section{References}

1. Qiao J, Han B. Diseases caused by mutations in lutenizing hormone/ chorionic gonadotropin receptor. In: Tao YX (ed). Progress in molecular biology and translational science: G protein signaling pathways in health and disease. Cambridge, Academic Press, 2019;69-89.

2. Shenker A, Laue L, Kosugi S, Merendino JJ Jr, Minegishi T, Cutler GB Jr. A constitutively activating mutation of the lutenizing hormone receptor in familial male precocious puberty. Nature 1993;365:652-654

3. Narayan P. Genetic models for the study of lutenizing hormone receptor function. Front Endocrinol (Lausanne) 2015;6:152

4. Lenz AM, Shulman D, Eugster EA, Rahhal S, Fuqua JS, Pescovitz OH, Lewis KA. Bicalutamide and third-generation aromatase inhibitors in testotoxicosis. Pediatrics 2010;126:728-733. Epub 2010 Aug 16

5. Lane LC, Flowers J, Johnstone H, Cheetham T. Adult height in patients with familial male-limited precocious puberty and the role of an aromatase inhibitor in patient management. J Pediatr Endocrinol Metab 2018;31:551-560.

6. Leschek EW, Flor AC, Bryant JC, Jones JV, Barnes KM, Cutler GB Jr Effect of antiandrogen, aromatase inhibitor, and gonadotropinreleasing hormone analog on adult height in familial male precocious puberty. J Pediatr 2017;190:229-235.

7. Mitre N, Lteif A. Treatment of familial male-limited precocious puberty (testotoxicosis) with anastrozole and bicalutamide in a boy with a novel mutation in the lutenizing hormone receptor. J Pediatr Endocrinol Metab 2009;22:1163-1167

8. Kreher NC, Pescovitz OH, Delameter P, Tiulpakov A, Hochberg Z. Treatment of familial male-limited precocious puberty with bicalutamide and anastrozole. J Pediatr 2006;149:416-420.

9. Schoelwer M, Eugster EA. Treatment of peripheral precocious puberty. Endocr Dev 2016;29:230-239. Epub 2015 Dec 17

10. Leschek EW, Jones J, Barnes KM, Hill SC, Cutler GB Jr. Six-year results of spironolactone and testolactone treatment of familial male-limited precocious puberty with addition of deslorelin after central puberty onset. J Clin Endocrinol Metab 1999;84:175-178.

11. Laue L, Kenigsbery D, Pescovitz OH, Hench KD, Barnes KM, Loriaux DL, Cutler GB Jr. Treatment of familial male precocious puberty with spironolactone and testosterone. N Engl J Med 1989;320:496-502.

12. Kor Y. Central precocious puberty in a case of late-diagnosed familial testotoxicosis and long-term treatment monitoring. Hormones (Athens) 2018;17:275-278. Epub 2018 May 7

13. Özcabı B, Tahmiscioğlu Bucak F, Ceylaner S, Özcan R, Büyükünal C, Ercan O, Tüysüz B, Evliyaoğlu O. Testotoxicosis: Report of two cases, one with a novel mutation in LHCGR gene. J Clin Res Pediatr Endocrinol 2015;7:242-248

14. Mauras N, Bell J, Snow BG, Winslow KL. Sperm analysis in growth hormone-deficient adolescents previously treated with an aromatase inhibitor: comparison with normal controls. Fertil Steril 2005;84:239. 242.

15. Juel Mortensen L, Blomberg Jensen M, Christiansen P, Rønholt AM, Jørgensen A, Frederiksen H, Nielsen JE, Loya AC, Grønkær Toft B. Germ cell neoplasia in situ and preserved fertility despite suppressed gonadotropins in a patient with testotoxicosis. J Clin Endocrinol Metab 2017;102:4411-4416. 
16. Müller J, Gondos B, Kosugi S, Mori T, Shenker A. Severe testotoxicosis phenotype associated with Asp578-- > Tyr mutation of the lutrophin/ choriogonadotrophin receptor gene. J Med Genet 1998;35:340-341.

17. Laue L, Chan WY, Hsueh AJ, Kudo M, Hsu SY, Wu SM, Blomberg L, Cutler GB Jr. Genetic heterogeneity of constitutively activating mutations of the human luteinizing hormone receptor in familial male-limited precocious puberty. Proc Natl Acad Sci USA 1995;92:1906-1910.

18. Kulshreshtha B, Mehta M, Gupta N, Ammini AC. Behavioral aggressiveness in boys with sexual precocity. Indian J Endocrinol Metab 2012;16:395-399.

19. Goede J, Hack WW, van der Voort-Doedens LM, Sijstermans K, Pierik $\mathrm{FH}$. Prevalence of testicular microlithiasis in asymptomatic males 0 to 19 years old. J Urol 2009;182:1516-1520. Epub 2009 Aug 15
20. Ganem JP, Workman KR, Shaban SF. Testicular microlithiasis is associated with testicular pathology. Urology 1999;53:209-213.

21. Dutra RA, Perez-Bóscollo AC, Melo EC, Cruvinel JC. Clinical importance and prevalence of testicular microlithiasis in pediatric patients. Acta Cir Bras 2011;26:387-390.

22. Gougoudi E, Zachariou Z, Kogia E, Zavitsanakis A. Testicular microlithiasis and Leydig cell proliferation in Wistar rats underwent Fowler-Stephens procedure. Pediatr Med Chir 2012;34:192-197. 